\title{
Transformação de lagoas de estabilização: reengenharia de um sistema obsoleto de tratamento de águas residuárias
}

\section{Transformation of waste stabilization ponds: reengineering of an obsolete wastewater treatment system}

Data de entrada: 02/06/2019

Data de aprovação: $18 / 06 / 2020$

\section{Resumo}

Lagoas de Estabilização (LEs) vêm sendo utilizadas há décadas para o tratamento de esgoto em cidades de médio e pequeno portes em muitos países do mundo. Esses sistemas são compostos por uma série de lagoas: (1) lagoa anaeróbia; (2) lagoas facultativas; e (3) lagoas de maturação. As LEs, em geral, produzem um efluente de boa qualidade, em termos de remoção de matéria orgânica e patógenos, mas sua aplicação apresenta desvantagens, sendo o longo tempo de permanência e a impossibilidade de remoção de nutrientes as mais notórias. Uma alternativa promissora ao uso das LEs é a substituição da série lagoa anaeróbia-lagoa facultativa por um reator UASB, que tem como vantagens a redução do tempo de permanência e a captação do biogás. Lagoas de pós-tratamento do efluente do reator UASB apresentam produção de oxigênio e consumo biológico de dióxido de carbono, o que eleva o pH. Nesta série de trabalhos mostra-se, por meio de investigações experimentais, que a produção de oxigênio abre a possibilidade de usar lagoas de polimento em regime de bateladas sequenciais em vez de fluxo contínuo. Essa modificação no regime hidrodinâmico acelera o decaimento das bactérias patogênicas, bem como propicia o aumento do $\mathrm{pH}$, que por sua vez possibilita a remoção dos seguintes nutrientes: nitrogênio, por meio da dessorção de amônia, e fósforo, pela precipitação de fosfato. Assim, produz-se um efluente de boa qualidade com baixas concentrações de material orgânico biodegradável, nutrientes (nitrogênio e fósforo) e patógenos. A boa qualidade do efluente é obtida em um sistema sem consumo de energia ou materiais auxiliares ao tratamento, e com uma área menor do que a de lagoas de estabilização convencionais.

Palavras-chave: Lagoas de estabilização. Reator UASB. Lagoa de polimento. Regime de bateladas sequenciais.

\section{Abstract}

Waste Stabilization Ponds (WSP) have been used for decades for the sewage treatment in medium and small cities in many countries. These systems are composed of a series of lagoons: (1) anaerobic pond (2) facultative pond lagoons and (3) maturation ponds. LEs in general produce a good quality effluent, in terms of organic matter and pathogens removal, but its application has disadvantages, being the long retention time the impossibility of nutrient removal the most serious ones. A promising alternative to the use of WSP is the replacement of the anaerobic

\footnotetext{
${ }^{1}$ Universidade Federal de Campina Grande - UFCG - Campina Grande - Paraíba - Brasil.

${ }^{2}$ Universidade Federal do Rio Grande do Norte - UFRN - Natal - Rio Grande do Norte - Brasil.

* Autor correspondente: adrianusvhagmail.com.
} 
pond + facultative pond by a UASB reactor, which has the advantages of greatly reducing the retention time. Pos$t$-treatment ponds of the UASB reactor effluent present oxygen production and biological consumption of carbon dioxide, which raises the $\mathrm{pH}$. This series of articles shows through experimental investigations that the production of oxygen opens the possibility of using polishing ponds in a sequential batch regime instead of continuous flow. This modification in the hydrodynamic regime accelerates the decay of pathogenic bacteria, as well as accelerates the increase in $\mathrm{pH}$, which in turn allows the removal of the following nutrients: nitrogen, through the desorption of ammonia, and phosphorus, by phosphate precipitation. This produces a good quality effluent with low concentrations of biodegradable organic material, nutrients (nitrogen and phosphorus) and pathogens. This good quality of the effluent is obtained in a system without energy consumption or auxiliary materials for treatment and with a smaller area than the one of conventional stabilization ponds.

Keywords: Waste stabilization ponds. UASB Reactor. Polishing ponds. Sequential batch regime.

\section{INTRODUÇÃO}

Quando, no início do século passado, o tratamento primário de esgoto mostrou-se insuficiente para a proteção dos recursos hídricos, foram desenvolvidas opções de tratamento secundário para os processos biológicos que permitisse remover o material orgânico. Uma delas foi o sistema de lagoas de estabilização de resíduos, que foi posteriormente aprimorado para aumentar sua capacidade de tratamento. Os resultados da experiência ao longo da primeira metade do século passado foram consolidados em um simpósio sobre lagoas de estabilização de resíduos, realizado em Kansas City, em 1960. O resultado mais importante extraído do simpósio foi a adoção do chamado sistema australiano, desenvolvido por Parker, Jones e Taylor (1950), que mostrou que a configuração ideal era a subdivisão do sistema de lagoas de estabilização em três partes (Fig. 1):

(a) Lagoa anaeróbia (LAn): projetada para receber esgoto bruto, com capacidade para remoção em torno de $50 \%$ da carga orgânica. Nela, os sólidos suspensos sedimentam no fundo, onde se desenvolve a digestão anaeróbia, resultando na transformação de parte do material orgânico do esgoto em biogás, que se desprende para a atmosfera. (b) Lagoa facultativa (LF): recebe o efluente da LAn. Nesse tipo de lagoa se desenvolve o processo de fotossíntese mediada por algas. A LF é caracterizada por uma camada superior aeróbia, como consequência do oxigênio dissolvido produzido pela fotossíntese, bem como da absorção de oxigênio do ar, e por uma camada inferior anaeróbia, onde ocorrem a digestão anaeróbia e o desprendimento de biogás espontâneo. 0 ambiente aeróbio é necessário para acelerar a remoção de material orgânico, uma vez que a digestão anaeróbia que remove material orgânico em ambiente anaeróbio se torna lenta quando sua concentração não é alta. Sendo assim, o critério de dimensionamento dessas lagoas é a área superficial.

(c) Lagoas de maturação (LM): recebem o efluente da LF e operam em um ambiente predominantemente aeróbio, havendo uma complementação da remoção do material orgânico nas $L M$, mas sua função principal é a remoção de indicadores de contaminação fecal, como as bactérias do grupo coliformes, por decaimento (CAVALCANTI; VAN HAANDEL; LETTINGA, 2001). Muitas vezes, as $L M$ são subdivididas para obterem uma redução acelerada desses organismos (MARAIS, 1974). A Fig. 1 mostra a configuração do sistema com a série de lagoas. 
A essência do sistema australiano é a predominância de um ambiente aeróbio em parte da LF, havendo um equilíbrio dinâmico entre a carga orgânica (que consome oxigênio) e a taxa de fotossíntese (que produz oxigênio). Como a taxa de fotossíntese é baixa, a carga orgânica não pode ser alta, de modo que o tempo de retenção deve ser longo; da ordem de 15 dias (MARA, 1997).

Um segundo desenvolvimento importante no projeto de lagoas de estabilização foi o reconhecimento de que o sistema de lagoas resulta em melhoria da qualidade higiênica do efluente. Marais e Shaw (1964) mostraram que o decaimento de coliformes termotolerantes poderia ser descrito como um processo de primeira ordem. Posteriormente, Marais (1974) desenvolveu um modelo de otimização de lagoas de estabilização para a remoção de coliformes termotolerantes. Compilando-se os modelos de Parker, Jones e Taylor (1950) e de Marais (1974), é possível projetar um sistema de lagoas de estabilização que remove eficientemente tanto material orgânico como organismos patogênicos.

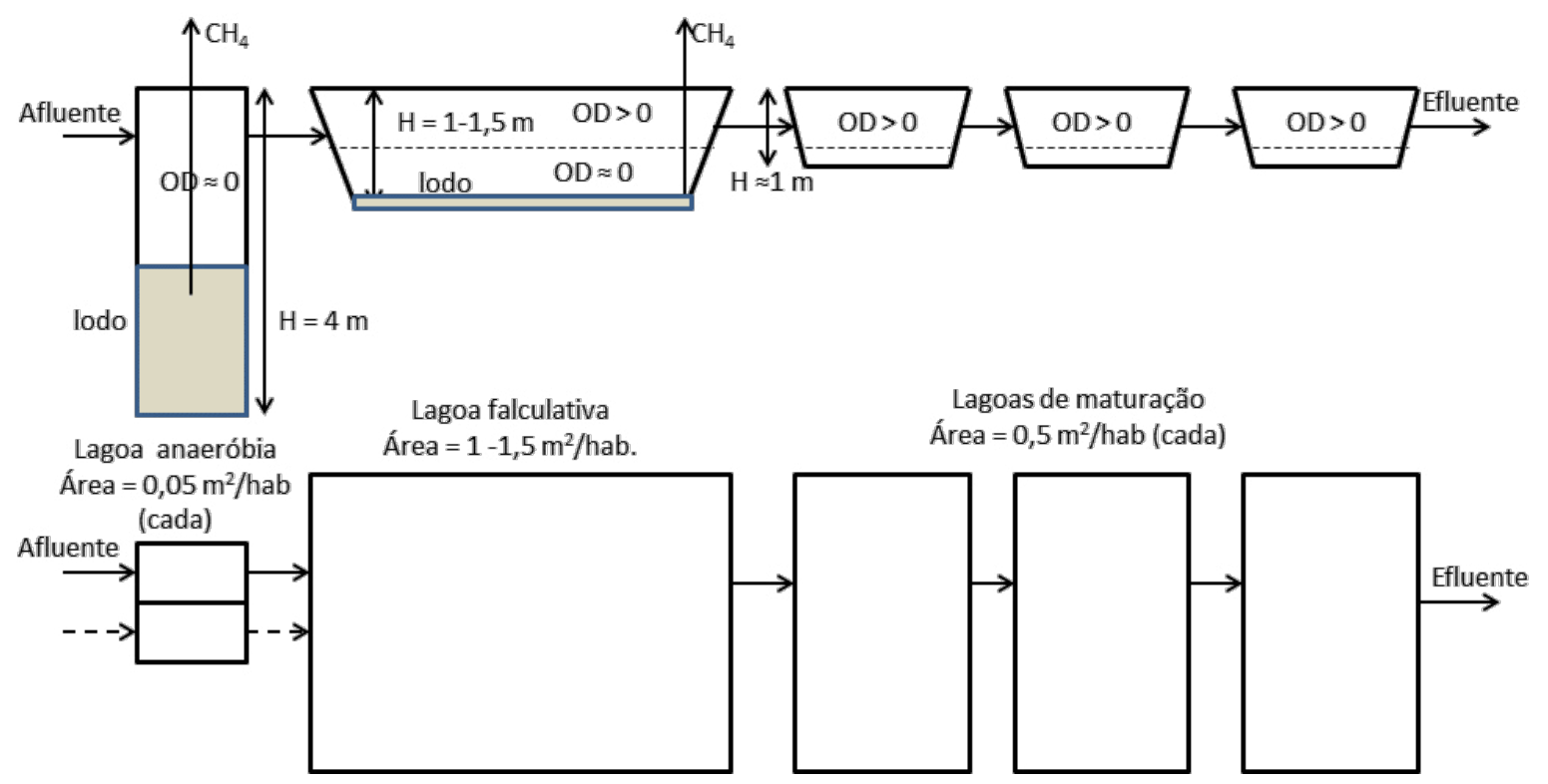

Figura 1 - Representação esquemática de um sistema convencional de lagoas de estabilização (LE), o sistema australiano.

Nos anos 60 do século passado, tornou-se evidente que, além da remoção do material orgânico e dos patógenos, a remoção dos nutrientes nitrogênio e fósforo é de vital importância para proteger os corpos receptores. Entretanto, pesquisas visando à remoção de nutrientes (PANO; MIDDLEBROOKS, 1982; BASTOS et al., 2018; ZIMMO; VAN DER STEEN; GIJZEN, 2003; CAMARGO VALERO; MARA, 2010) mostraram que a remoção de nitrogênio é somente parcial e a remoção de fósforo não é factível. A razão desse insucesso se deve ao principalmente ao $\mathrm{pH}$, que em lagoas de estabilização mantém-se praticamente neutro. Nesta série de artigos mostra-se que para uma remoção eficiente de nutrientes é necessário que o $\mathrm{pH}$ aumente significativamente.

Lagoas de Estabilização (LEs) vêm sendo utilizadas para o tratamento de esgoto em cidades de médio e pequeno porte no Brasil e em muitos 
países há décadas. O Instituto Brasileiro de Geografia e Estatística (IBGE) afirma que do total de esgoto tratado (em torno de $8.500 .000 \mathrm{~m}^{3} / \mathrm{d}$ ), aproximadamente $50 \%$ se realiza em sistemas de lagoas de estabilização (IBGE, 2010). Ho Echelpoel e Goethals (2017) mostraram que mesmo em regiões de clima não favorável as LEs são amplamente aplicadas: nos Estados Unidos, na França e na Alemanha o número de LEs é de 50, 20 e $30 \%$ do total de número de ETEs, respectivamente. Invariavelmente, as LEs são operadas em regime de fluxo contínuo. Na configuração australiana, esses sistemas podem produzir uma boa qualidade para o efluente em termos de remoção da Demanda Bioquímica de Oxigênio (DBO) e dos patógenos (MARA, 1976), mas a remoção de nutrientes é insatisfatória.

O sistema de lagoas de estabilização apresenta algumas vantagens, mas também tem desvantagens. As vantagens estão associadas à sua simplicidade operacional e ao baixo custo de implantação (se houver condições topográficas favoráveis e área disponível a baixo custo). As desvantagens são várias, sendo as principais:

(1) A produção de oxigênio é lenta, portanto, as áreas das LEs devem ser elevadas (tempo de permanência total de 1 mês aproximadamente; área necessária $3 \mathrm{~m}^{2} /$ habitante; MARA, 1976) para manter um ambiente ao menos parcialmente aeróbio na lagoa facultativa e predominantemente aeróbio nas lagoas de maturação. Isso é necessário para uma remoção eficiente do material orgânico, mas inviabiliza a sua aplicação nos grandes centros urbanos;

(2) A consequência da grande área das LEs é que há uma perda grande de água por evaporação, acarretando em um aumento da salinidade do efluente, prejudicando sua aplicabilidade como água de reúso para fins de irrigação (MARA; PEARSON, 1998);
(3) As LEs não são adequadas para a remoção de nutrientes (nitrogênio e fósforo), de modo que, se lançadas em corpos d'água, podem desencadear o processo da eutrofização.

(4) A aplicação da LAn resulta na produção de biogás que se desprende da fase líquida e gera maus odores no entorno do sistema de LE (presença de gás sulfídrico), o que contribui para a impopularidade das LEs junto à população (CAMPOS, 1999);

(5) O biogás que se desprende da LAn representa um problema ambiental: o metano no biogás contribui de maneira importante para a liberação de gases do efeito estufa, que é 21 vezes mais prejudicial que o $\mathrm{CO}_{2}$. A "pegada ambiental" das LEs é bem maior do que a de sistemas aeróbios de tratamento (VAN HAANDEL; VAN DER LUBBE, 2019);

(6) Há uma acumulação importante de sólidos não biodegradáveis na LAn, o que resulta no assoreamento desta e leva à necessidade de remoção dos sólidos (cada 3 a 5 anos), uma operação complicada (CAVALCANTI, 2003; OAKLEY, 2005);

(7) A necessidade de afastar a lagoa com seus odores da região urbana implica em um custo extra da rede de coleta com um emissário longo, o que representa um fator de investimento de grande importância;

(8) O mesmo problema de odores requer que se opere um único sistema de LEs, não sendo possível segmentar a rede de esgoto para tratamento em sistemas descentralizados no fim das redes e assim, reduzir custos da infraestrutura.

Nos últimos anos, pôde-se observar uma tendência de diminuição do uso da lagoa anaeróbia, talvez por causa da rejeição pela população. A eliminação da LAn exige um aumento considerável da área da $L F$, já que esta recebe agora o esgoto bruto, o que aumenta a demanda de oxigênio para degradar o material orgânico. Como a 
LAn, em muitos casos, remove em torno da metade do material biodegradável (JORDÃO; PÊSSOA, 2017), a LF que recebe esgoto bruto deve, no mínimo, ser duas vezes maior que uma LF precedida por uma LAn.

Na prática, essa providência resolve alguns problemas das LEs, mas cria outros. Certamente haverá redução dos odores gerados no sistema, mas o aumento da área faz com que problemas como a evaporação e a associada deterioração da qualidade do efluente final (salinidade) aumentem. Outro ponto é que os sólidos não biodegradáveis do esgoto se acumulam na lagoa facultativa, o que por um lado aumenta o tempo de assoreamento, mas, por outro lado, cria um problema quase impossível de ser resolvido quando a lagoa fica cheia de sólidos, uma vez que não se tem uma segunda LF, como tem uma segunda LAn no sistema convencional.

\section{MODIFICAÇÕES PROPOSTAS NO SISTEMA CONVENCIONAL DE LAGOAS DE ESTABILIZAÇÃO}

Há basicamente duas maneiras de reduzir os problemas que são inerentes à aplicação das LEs: (1) diminuir a demanda por oxigênio; ou (2) aumentar a geração deste. Para diminuir a demanda por oxigênio, é necessário que se aumente a eficiência da digestão anaeróbia que se desenvolve na LAn. Isso é possível quando se aplica um reator eficiente como, por exemplo, o reator UASB, que tende a ter uma eficiência superior à LAn e LF combinadas (VAN HAANDEL; LETTIN$G A, 1994)$. O reator tem a vantagem adicional de captar o biogás, que pode ser queimado para evitar que os maus odores se espalhem na região do entorno do sistema. Além disso, ao se capturar e queimar o biogás, o metano é convertido em dióxido de carbono, reduzindo a emissão de gases do efeito estufa. Por outro lado, o lodo gerado no reator UASB pode ser descarregado como lodo de excesso e, após secagem, ser aproveitado como adubo orgânico e dessa maneira não se acumular no sistema de tratamento. Adicionalmente, o efluente do reator UASB apresenta uma baixa turbidez em razão da remoção de grande parte dos sólidos suspensos do esgoto, o que resulta numa maior transparência do líquido na lagoa que recebe seu efluente, e consequentemente, uma taxa de fotossíntese maior porque a radiação solar pode penetrar mais profundamente na lagoa. Assim, a aplicação do reator UASB resulta tanto numa diminuição da demanda de oxigênio no efluentecomo em um aumento da sua produção fotossintética. Por essas razões, a lagoa subsequente pode ser operada com uma área menor. Portanto, a simples aplicação do reator UASB em si já traz vantagens importantes.

A área da LE é grande porque a lagoa facultativa deve operar de forma a favorecer condições aeróbias, uma vez que em ambiente anaeróbio a remoção do material orgânico é mais lenta. Por essa razão, opera-se a LF como uma lagoa cujo regime hidráulico se aproxima da mistura completa, onde se introduz paulatinamente o efluente da LAn, de modo a distribuir a demanda de oxigênio associada uniformemente sobre toda a lagoa. Dimensiona-se a LF de tal maneira que a demanda média de oxigênio pelo material orgânico introduzido da LAn não exceda a produção de oxigênio pela fotossíntese e pela transferência de oxigênio atmosférico, mantendo-se, assim, um ambiente aeróbio permanente em pelo menos parte da LF.

Uma alternativa de pós-tratamento desses efluentes anaeróbios é o uso de lagoas que são denominadas lagoas de polimento (LPs), diferenciando-se das lagoas de estabilização convencionais (LEs) usadas para o tratamento de esgoto bruto (CAVALCANTI, 2003). Embora as concentrações residuais de material orgânico e de sólidos em suspensão nos reatores UASB geralmente sejam superiores ao limite legal estabelecido 
para descarga em águas de superfície, o pós-tratamento se torna mais fácil. Ademais, a qualidade do efluente do reator UASB é relativamente boa e permite eliminar mais facilmente outros constituintes indesejáveis do esgoto, como patógenos e nutrientes. Portanto, a necessidade de pós-tratamento se impõe para reduzir a concentração residual de material orgânico e os patógenos, mas essa redução é facilitada por uma digestão anaeróbia eficiente que se desenvolve no reator UASB. Por ter uma qualidade melhor que o esgoto bruto, a configuração e a operação, bem como os objetivos de uma LP, serão muito diferentes em um sistema de LEs convencional que trata esgoto bruto.

Na Fig. 2 compara-se a remoção da DBO em uma LE e em um sistema UASB seguido de LP. Como a demanda de oxigênio no efluente do UASB será menor, a área da lagoa pode ser reduzida. Quanto à operação, a menor demanda abre a perspectiva de operar a lagoa no regime de bateladas sequenciais (LPBS), em vez de fluxo contínuo (LPFC). Potencialmente, a operação da LPBS tem grande vantagem, podendo reduzir o tempo de permanência para remover a DBO, patógenos e nutrientes. Para otimizar o sistema UASB seguido de LP é necessário que se investigue: (1) a viabilidade de operar a lagoa de polimento em regime de bateladas sequenciais para tratar o efluente de um reator UASB; (2) quais são os limites de operação em regime de bateladas; e (3) quais são as vantagens de operar lagoas como pós-tratamento do reator UASB em regime de bateladas em vez de fluxo contínuo.

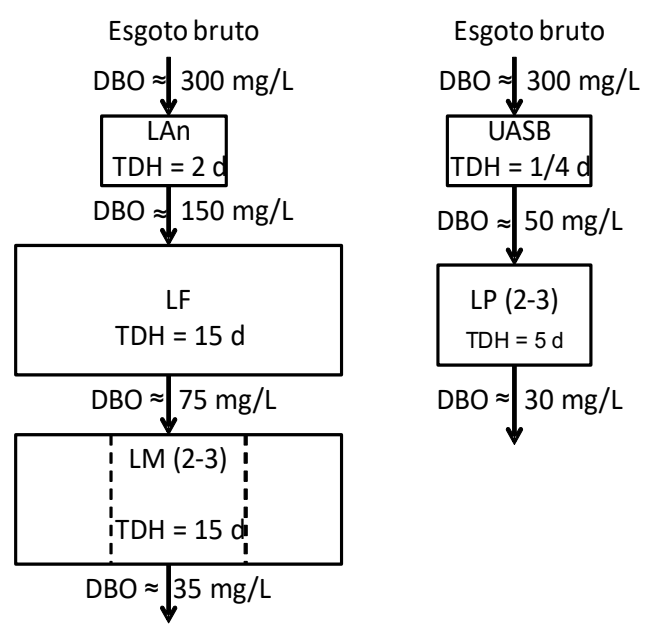

Figura 2 - Valores comparativos da DBO e do tempo de permanência em um sistema de LE convencional e em um sistema UASB-LP (em regime de batelada).

Ao considerar que a remoção de DBO residual se completa em pouco tempo em uma LP, a remoção de Coliformes Termotolerantes (CTT) normalmente é o processo que determina o tempo de permanência mínimo, quando não se deseja também a remoção de nutrientes. Sabendo que o decaimento de CTT é um processo de primeira ordem (VAN HAANDEL; LETTINGA, 1994), a operação em uma LPBS é muito vantajosa. A teoria de reatores na engenharia química, relativa a processos de primeira ordem, mostra que reatores de bateladas sequenciais sempre são mais eficientes que reatores de fluxo contínuo, e a diferença aumenta na medida em que aumenta a 
eficiência desejada (LEVENSPIEL, 2003). Quando a remoção de nutrientes é um objetivo da LP, a vantagem da operação de bateladas sequenciais se torna ainda maior. Cavalcanti (2003) mostrou que na operação de LP em regime de fluxo contínuo a remoção de fósforo é parcial e instável.

No início da operação das lagoas em bateladas sequenciais, a demanda por oxigênio é máxima e a produção fotossintética é mínima, uma vez que a população de algas ainda não está desenvolvida. Se a demanda por oxigênio for maior que a produção e a transferência de oxigênio, ainda é possível operar uma lagoa em regime de bateladas ao se inocular a batelada com algas e, assim, assegurar uma produção biológica de oxigênio desde o início da operação. É importante notar que essa opção de lagoa em regime de bateladas não existe no caso da LF recebendo efluente da LAn: neste caso, a demanda por oxigênio do efluente da LAn sempre é bem maior que o potencial de produção; quando a LF é operada em regime de batelada, o ambiente nela será anaeróbio e permanecerá assim até que a digestão anaeróbia remova uma concentração suficiente de material biodegradá- vel para que a demanda e a produção de oxigênio nas lagoas se equilibrem e um ambiente aeróbio possa começar a se estabelecer, o que pode ser um processo demorado.

A Tabela 1 mostra as diferenças entre o sistema convencional de lagoas de estabilização (LEs), tratando esgoto bruto, e de lagoas de polimento (LPs), tratando efluente do reator UASB. As vantagens da LP não se limitam aos aspectos do sistema de tratamento propriamente dito (menor área, menos evaporação, inodoro, uso do lodo como adubo, possibilidade de remoção de nutrientes), mas também em termos da rede coletora de esgoto (emissários mais curtos/possibilidade de segmentação da rede em cidades grandes com mais de um sistema de tratamento). A redução de custos devido ao menor emissário e segmentação da rede é considerável, e muitas vezes o investimento na coleta e no tratamento de esgoto com um sistema composto de rede de coleta - reator UASB - LP pode ser menor que o investimento quando comparado ao sistema de rede coletora - LE convencional, devido à redução de custos da rede de esgoto.

Tabela 1 - Diferenças entre lagoa de estabilização (LE) e lagoa de polimento (LP).

\begin{tabular}{|c|c|c|}
\hline Parâmetro & Lagoa de estabilização (LE) & Lagoa de polimento (LP) \\
\hline Afluente & Esgoto bruto & Esgoto digerido \\
\hline Objetivo (s) principal (is) & Remoção do MO e SST & Remoção de patógenos e de nutrientes (quando desejada) \\
\hline Configuração & Lagoas em série (LAn-LF-LM) & Várias lagoas em regime de bateladas sequenciais (LPBS) \\
\hline Regime de escoamento desejável & Fluxo contínuo em lagoas de mistura parcial ou completa & Lagoas em regime de bateladas sequenciais \\
\hline $\begin{array}{l}\text { Tempo de permanência } \\
\text { (em clima quente) }\end{array}$ & Na faixa de 1 mês para remoção da DBO e CTT & $\begin{array}{c}\text { Tempo depende da profundidade. Para remoção da } \\
\text { DBO e dos CTT < } 1 \text { semana } \\
\text { Remoção de Nutrientes }<2 \text { semanas }\end{array}$ \\
\hline Desprendimento de biogás & $\begin{array}{l}\text { Liberado à atmosfera contribuindo para o efeito estufa e } \\
\text { causando maus odores }\end{array}$ & $\begin{array}{l}\text { Biogás é gerado no reator UASB queimado ou usado para } \\
\text { geração de energia; não há problemas de odor }\end{array}$ \\
\hline Lodo no fundo & Acumulação rápida na LAn $(250$ mg/L) & Acumulação lenta $(70$ mg/L) \\
\hline Área de aplicação & Longe de regiões urbanas (odores), longos emissários & Proximidade da população não traz problemas \\
\hline Profundidade & $>1 \mathrm{~m}$ & $\approx 0,5 \mathrm{~m}$ \\
\hline Topografia & Necessariamente plano & LPBS podem ter níveis diferentes \\
\hline Remoção de nutrientes & Pouca ou nenhuma & Remoção de $\mathrm{NH}_{3}$ e P é factível \\
\hline Custo de investimento & $\begin{array}{l}\text { Alto pelo afastamento necessário do sistema da região } \\
\text { urbana }\end{array}$ & $\begin{array}{c}\text { Redução de custos por vários sistemas de tratamento } \\
\text { numa cidade (rede segmentada) }\end{array}$ \\
\hline
\end{tabular}

O tratamento em LP não se limita à remoção da DBO e dos CTT. Devido ao fato do consumo de
$\mathrm{CO}_{2}$ para a fotossíntese ser maior que a taxa de produção, pela oxidação de material orgânico, 
a acidez da lagoa diminui e o pH aumenta. Esse aumento do $\mathrm{pH}$ pode possibilitar a remoção de nutrientes por dois mecanismos distintos:

(1) A remoção de nitrogênio amoniacal (forma predominante de nitrogênio no efluente do reator UASB) se torna possível pelo aumento da concentração de amônia na forma gasosa (NH3), que se deve ao deslocamento do equilíbrio quando o $\mathrm{pH}$ aumenta. A concentração mais elevada de $\mathrm{NH}_{3}$, por sua vez, possibilita o desprendimento do gás.

(2) $\mathrm{O}$ pH elevado afeta também a dissociação do fosfato (a forma predominante de fósforo em efluente do UASB) e aumenta a forma de $\mathrm{PO}_{4}{ }^{3-}$ na medida em que o $\mathrm{pH}$ se aproxima do valor da constante de dissociação de $\mathrm{HPO}_{4}{ }^{2-}$ para $\mathrm{PO}_{4}{ }^{3-}\left(\mathrm{pK}_{3}=\right.$ $12,2)$. Isso, por sua vez, possibilita a precipitação de fosfatos e a remoção de fósforo da fase líquida.

Portanto, o pré-requisito para a remoção de $\mathrm{Ne}$ $P$ é o aumento significativo do $\mathrm{pH}$ na lagoa, que por sua vez somente é possível se o consumo de $\mathrm{CO}_{2}$ na fotossíntese for maior que a produção pela oxidação. Conclui-se que a remoção de $\mathrm{Ne}$ $P$ não é possível em sistemas convencionais de LE, onde os dois processos estão em equilíbrio. De fato há pouca remoção de nutrientes em LE. Por essa razão, a rigor os efluentes não poderiam ser lançados em águas de superfície, como na prática geralmente acontece. Neste caso, a qualidade do efluente deveria estar de acordo com os padrões de qualidade exigidos pelas $\mathrm{Re}$ soluções $n^{\circ} 357 / 2005$ e n 430/2011 do Conselho Nacional do Meio Ambiente - Conama
(BRASIL, 2005, 2011), que impõem limites para a concentração de nutrientes.

\section{PROCESSOS QUE SE DESENVOLVEM EM LAGOAS}

Nos sistemas de tratamento por lagoas, desenvolvem-se vários processos bioquímicos, físicos e químicos que resultam na redução de constituintes indesejáveis do esgoto. Com relação à remoção de material orgânico há três processos bioquímicos que podem se desenvolver simultaneamente (VAN HAANDEL; VAN DER LUBBE, 2019):

(1) No ambiente anaeróbio (LAn e parte inferior da LF) há digestão anaeróbia que resulta na produção de biogás a partir da fermentação do material orgânico (MO):

$\mathrm{MO} \rightarrow \mathrm{CH}_{4}+\mathrm{CO}_{2}$

(2) No ambiente aeróbio, há oxidação do material orgânico que resulta no consumo de oxigênio e na geração de dióxido de carbono:

$\mathrm{MO}+\mathrm{O}_{2} \rightarrow \mathrm{CO}_{2}+\mathrm{H}_{2} \mathrm{O}$

(3) Paralelamente, há a fotossíntese, que na sua essência é o processo inverso ao da oxidação: produção de material orgânico e oxigênio a partir de dióxido de carbono e água:

$\mathrm{CO}_{2}+\mathrm{H}_{2} \mathrm{O} \rightarrow \mathrm{MO}+\mathrm{O}_{2}$

A Fig. 3 mostra esquematicamente o desenvolvimento dos três processos.

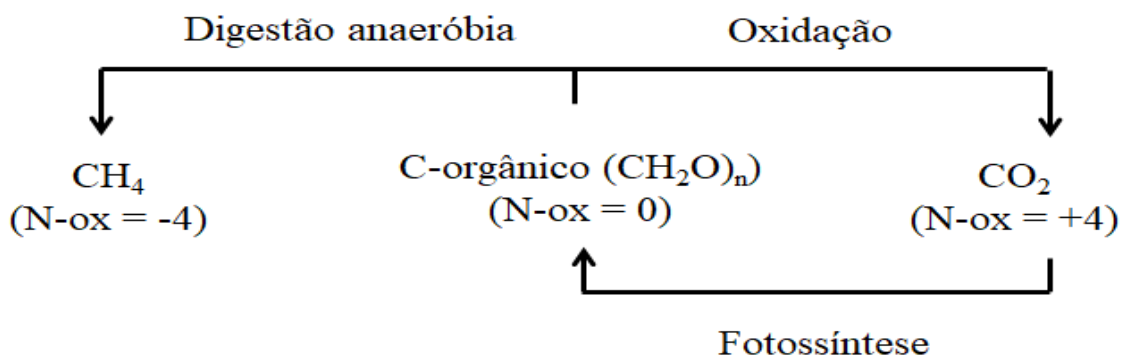

Figura 3 - Representação esquemática dos processos biológicos que ocorrem em lagoas tratando águas residuárias. 
A taxa e a extensão dos processos bioquímicos em LEs e LPs são muito diferentes. Enquanto nas LAns e LFs a digestão anaeróbia é responsável pela remoção de grande parte do material orgânico, esse processo tem pouca ou nenhuma influência nas LPs. Nestas, os processos mais importantes são a oxidação do material orgânico e a fotossíntese. Ao analisar os processos de oxidação e a fotossíntese (Eq. 2 e 3), pode-se notar que os processos são complementares: os reatantes de um são os produtos do outro. Se a taxa de fotossíntese for menor que a taxa de consumo de oxigênio, a concentração de oxigênio será menor que a concentração de saturação, mas o ambiente pode permanecer aeróbio se houver absorção de oxigênio do ar suficiente para compensar o déficit. Nessa situação, a produção de oxigênio é menor que o consumo, o que resulta numa produção de $\mathrm{CO}_{2}$ que por sua vez tende a causar uma diminuição do $\mathrm{pH}$. Se a absorção não for suficiente para compensar o déficit, o oxigênio dissolvido acabará sendo consumido e a lagoa poderá ficar anaeróbia.

Se a taxa de fotossíntese for maior que a taxa de consumo, a concentração de oxigênio tenderá a subir e a lagoa poderá ficar supersaturada com oxigênio. Essa é uma situação que normalmente ocorre quando o efluente do reator UASB é lançado em uma LP, porque a concentração de material orgânico é baixa, diminuindo o consumo de OD, e tornando-a mais transparente, aumentando assim a taxa de fotossíntese. Nesse caso, em princípio há um aumento da concentração de material orgânico, mas esse aumento pode não se materializar devido à floculação e sedimentação das algas. Sempre que houver produção líquida de OD, necessariamente há consumo biológico de $\mathrm{CO}_{2}$, o que resulta num aumento do $\mathrm{pH}$ da lagoa.

Paralelamente aos processos bioquímicos, também há processos físicos e químicos que se de- senvolvem na lagoa como indica a Fig. 4. Processos físicos são os processos de dessorção ou absorção de compostos voláteis que se encontram no efluente do UASB ou são gerados nas lagoas. Esses compostos são: amônia, dióxido de carbono, oxigênio dissolvido (OD), metano e gás sulfídrico. No caso de $\mathrm{H}_{2} \mathrm{~S}, \mathrm{NH}_{3}$ e $\mathrm{CH}_{4}$ há dessorção porque esses gases não têm concentração mensurável no ar. No caso de $\mathrm{CO}_{2}$ e $\mathrm{O}_{2}$ pode haver tanto dessorção como absorção, dependendo de se a concentração dos compostos na fase líquida é maior ou menor que a concentração de saturação. Os processos de absorção ou dessorção podem ser descritos com a Equação de Fick (Eq. 4), que afirma que a taxa de dessorção de um composto volátil num líquido é proporcional ao grau de supersaturação que existe entre a concentração atual do composto e a concentração de saturação:

$r_{d}=k_{a}\left(C_{1}-C_{s}\right)$

Em que:

$r_{d}=$ taxa de dessorção do composto volátil

$\mathrm{k}_{\mathrm{a}}=$ constante de dessorção

$\mathrm{C}_{\mathrm{s}}=$ constante de saturação do composto volátil

$\mathrm{C}_{1}=$ constante do composto volátil no líquido

Assim, tem-se:

$r_{d N}=k_{d N}\left[N_{3}\right]$

$r_{d o}=k_{d o}\left([D O]-[D O]_{s}\right)$

$r_{d c}=k_{d c}\left(\left[\mathrm{CO}_{2}\right]-\left[\mathrm{CO}_{2}\right]_{s}\right)$

A dessorção de $\mathrm{OD}$ e $\mathrm{CH}_{4}$ não afeta nem a alcalinidade nem a acidez, e por isso também não afeta o $\mathrm{pH}$. A dessorção de $\mathrm{H}_{2} \mathrm{~S}$, embora perceptível, é muito pequena $(<0,5 \mathrm{meq} / \mathrm{L})$ e também não afeta o pH. A dessorção do ácido $\mathrm{CO}_{2}$ diminui a acidez e por isso aumenta o pH. A dessorção de amônia aumenta a acidez e diminui a alcalinidade, e por isso tende a diminuir o $\mathrm{pH}$. 


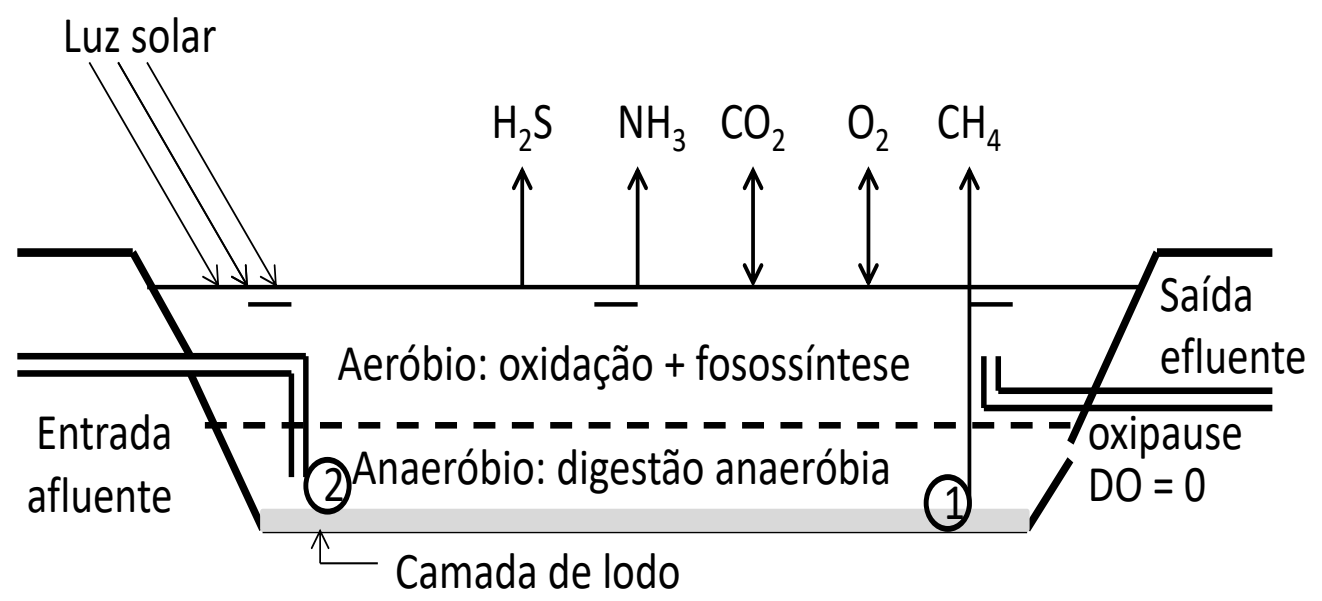

Figura 4 - Representação esquemática de uma lagoa para o tratamento de águas residuárias e os processos físicos que nela podem se desenvolver.

Outro processo físico que se desenvolve nas lagoas é a sedimentação de sólidos, que podem entrar junto com o afluente ou se formar devido à floculação das algas que crescem na lagoa. Esses sólidos são transformados parcialmente em biogás (metano) pelo processo de digestão anaeróbia ou se acumulam no fundo da lagoa como uma camada de lodo.

Um processo químico importante é a precipitação de sais de fosfato. Este só se desenvolve quando há um aumento substancial do $\mathrm{pH}$ na lagoa, o que pode acontecer somente em lagoas do tipo LP, onde a fotossíntese predomina sobre a oxidação. Em condições adequadas pode ha- ver ainda a precipitação de carbonato de cálcio, quando o $\mathrm{pH}$ aumenta suficientemente.

Nem todos os processos mencionados se desenvolvem com taxa significativa em todas as lagoas. Na Tabela 2, pode-se observar para diferentes tipos de lagoas (LAn, LF, LP, LM) quais os processos bioquímicos ocorrem (O), podendo ser predominante $(\mathrm{P})$ ou não ocorrer $(\mathrm{N})$ de maneira perceptível. Quanto aos processos físicos, eles se distinguem entre Dessorção (D) e Absorção (A), podendo ainda esses processos não acontecerem (N). A precipitação de fosfato pode ocorrer nas LP em regime de bateladas, mas não nas lagoas de outros tipos (CAVALCANTI, 2003).

Tabela 2 - Processos que podem (ou não) se desenvolver em lagoas de diferentes tipos.

\begin{tabular}{|c|c|c|c|c|c|c|c|}
\hline \multirow{3}{*}{ Lagoas } & \multicolumn{7}{|c|}{ Processos } \\
\hline & \multicolumn{3}{|c|}{ Bioquímico } & \multicolumn{3}{|c|}{ Físico: absorção/dessorção } & \multirow{2}{*}{$\begin{array}{c}\text { Químico } \\
\text { Precipitação P }\end{array}$} \\
\hline & Fotos-síntese & Oxidação & $\begin{array}{c}\text { Digestão } \\
\text { anaeróbia }\end{array}$ & $\mathrm{NH}_{3}$ & OD & $\mathrm{CO}_{2}$ & \\
\hline LP & $\mathrm{P}$ & 0 & $\mathrm{~N}$ & $\mathrm{D}$ & $\mathrm{D}$ & $\mathrm{D}$ & 0 \\
\hline LAn & $\mathrm{N}$ & $\mathrm{N}$ & $P$ & $\mathrm{~N}$ & A & $\mathrm{D}$ & $\mathrm{N}$ \\
\hline LF & 0 & 0 & 0 & $\mathrm{~N}$ & A & $\mathrm{D}$ & $\mathrm{N}$ \\
\hline LM & $P$ & $\mathrm{O}$ & $\mathrm{O}$ & $\mathrm{N}$ & $\mathrm{D} / \mathrm{A}$ & $\mathrm{D} / \mathrm{A}$ & $\mathrm{N}$ \\
\hline
\end{tabular}

Legenda: $P$ = predominante; $O=$ ocorre; $N$ = não ocorre; $D=$ Dessorção; e $A$ = Absorção. 


\section{OBJETIVOS DO TRATAMENTO DAS LAGOAS DE POLIMENTO}

O objetivo do tratamento nas LPs é produzir um efluente final que esteja compatível com as normas impostas pela legislação. Se o efluente final for lançado em águas de superfície, há 4 componentes problemáticos no efluente do reator UASB e que devem ser corrigidos pelo tratamento nas LPs: (1) redução da concentração de material orgânico; (2) dos patógenos, e dos nutrientes; (3) nitrogênio e (4) fósforo. Na Fig. 5 pode-se observar a variação dos cinco componentes (OD, $\mathrm{pH}$, material orgânico, nitrogênio amoniacal e ortofosfato) em função do tempo para diferentes profundidades de LPBS e diferentes condições climáticas (verão, ao lado esquerdo e inverno, ao lado direito). Os resultados podem ser resumidos como se segue:

(1) Realizaram-se investigações com profundidades variando entre $0,2 \mathrm{~m}$ a $1,0 \mathrm{~m}$;

(2) Albuquerque, Santos e van Haandel (2021) mostraram que o uso do regime de bateladas sequenciais de lagoas de polimento (LPBS) não somente é factível após pré-tratamento anaeróbio eficiente, mas que tem grande vantagem aplicálo em vez de lagoas de fluxo contínuo (LPFC);

(3) Para todas as profundidades, a concentração de OD aumentou com o tempo, sendo mais rápido em LPBS rasas;

(4) Aguiar, Santos e van Haandel (2021) mostraram que a remoção de material orgânico residual (tanto DBO como DQO) é rápida e, dentre os quatro componentes a serem removidos, é o que requer a menor área;

(5) Batista et al. (2021) mostraram que a remoção de coliformes requer uma área muito menor em LPBS do que em LPFC, porque o decaimento bacteriano é um processo de primeira ordem;

(6) O clima tem uma clara influência sobre a remoção dos nutrientes: $\mathrm{N}$ e P. Assim, a área neces- sária no inverno é maior que no verão, devido à menor taxa de fotossíntese;

(7) Santos e van Haandel (2021) mostraram que o mecanismo de remoção de nitrogênio é a dessorção de amônia. Para esse processo se desenvolver é necessário que o pH aumente, e isso só se verifica quando a taxa de produção de oxigênio (taxa de fotossíntese) é maior do que a taxa de consumo de oxigênio por oxidação de material orgânico. As características do efluente do UASB favorecem o aumento do $\mathrm{pH}$ porque há boa transparência (facilitando a fotossíntese) e baixa concentração de material orgânico (reduzindo a taxa de oxidação). A remoção quase completa de nitrogênio em LPBS é possível e se materializa em profundidade rasa; para profundidades acima de $1 \mathrm{~m}$, o aumento do pH e a dessorção de amônia são lentos. Remoção de nitrogênio em LPFC é possível, mas a área necessária da lagoa é bem maior que para as LPBS;

(8) Santos, Santos e van Haandel (2021) mostraram que a remoção de fósforo é possível quando o pH é elevado devido à precipitação de hidroxiapatita de cálcio $\left(\mathrm{Ca}_{5}(\mathrm{OH})\left(\mathrm{PO}_{4}\right)^{3}\right)$. Na investigação experimental, utilizou-se esgoto doméstico que continha uma concentração de $1 \mathrm{mmol} / \mathrm{L}$ de $\mathrm{Ca}$; nessas condições foi necessário atingir $\mathrm{pH}$ de aproximadamente 9,7 para obter baixa concentração residual de fósforo ( $<1 \mathrm{mgP} / \mathrm{L}$ ). Esse $\mathrm{pH}$ pode ser atingido em LPBS rasas, mas a área necessária da lagoa é aproximadamente o dobro da área para remoção eficiente de nitrogênio. Em LPFC a remoção de fósforo é parcial, mesmo em lagoas rasas, porque o $\mathrm{pH}$ não aumenta suficientemente;

(9) A profundidade das lagoas teve uma grande influência sobre a remoção dos nutrientes, nitrogênio e fósforo, mas pouco afetou a área necessária para a remoção de material orgânico e dos coliformes;

(10) Em todos os casos pesquisados sempre a concentração de $\mathrm{N}$ e $\mathrm{P}$ na fase sólida da suspensão nas LPBS foi menor de $1 \mathrm{mg} / \mathrm{L}$. 

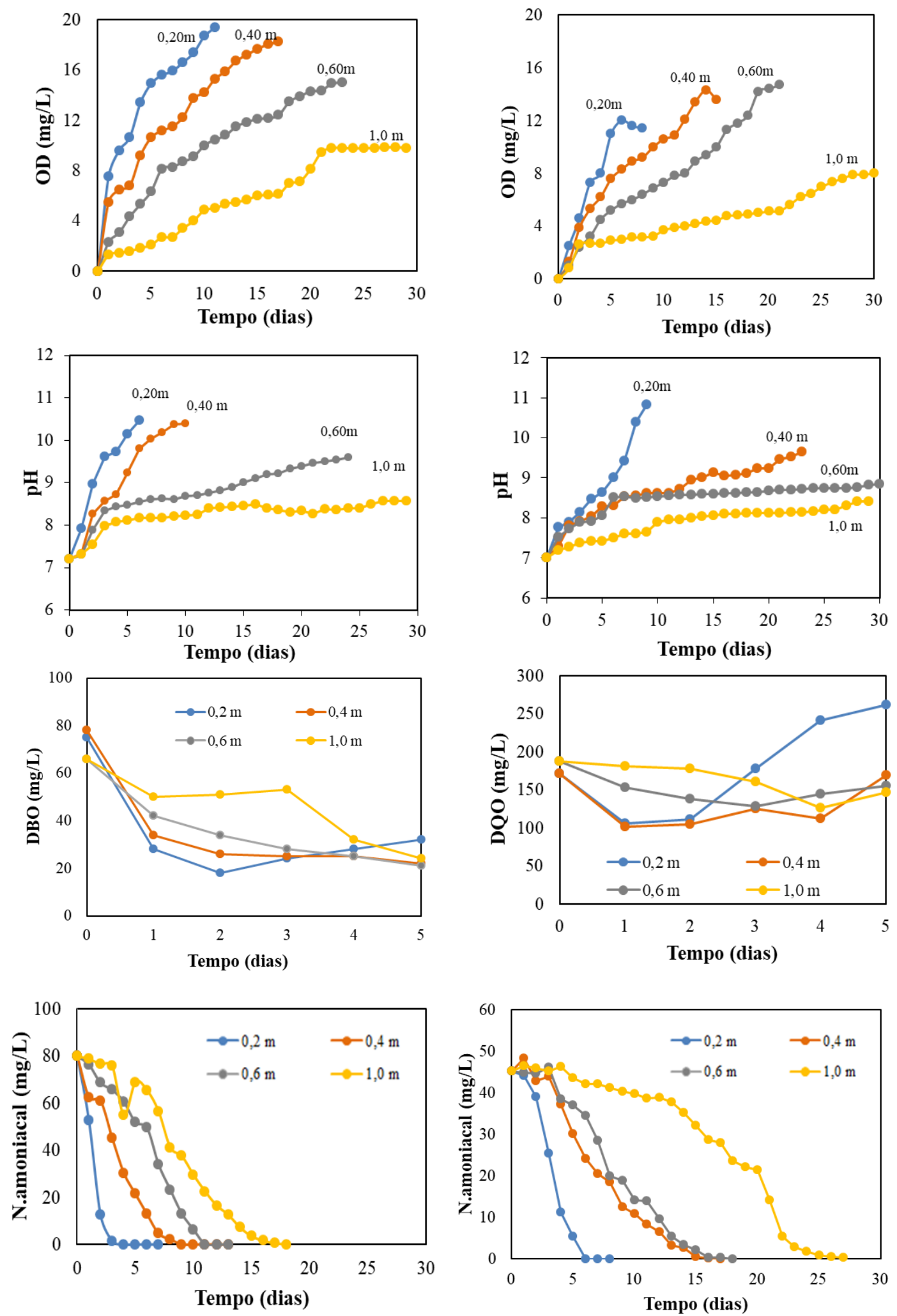

Figura 5 - Resultados experimentais da variação da concentração de OD, pH, material orgânico (DBO e DQQ somente para o inverno), nitrogênio amoniacal e ortofosfato em LPBS em função do tempo de permanência para diferentes profundidades e condições de verão (esquerda) e inverno (direita).

continua... 
Figura 5 - Continuação...

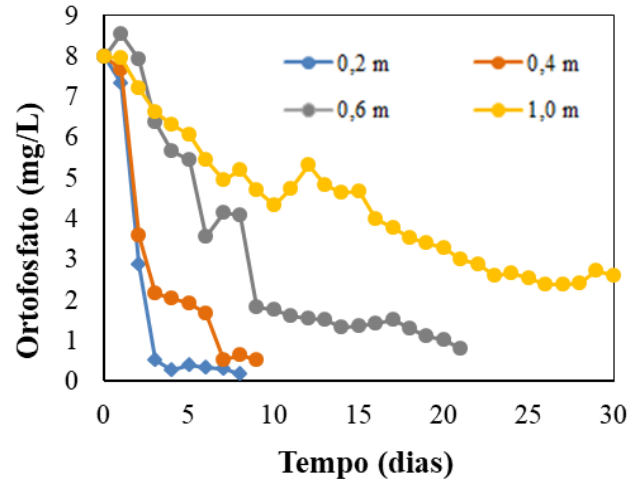

Na prática, a variável mais importante é a área necessária para o tratamento. Essa área é relacionada ao tempo de permanência da seguinte maneira:

$A_{\text {hab }}=V_{\text {hab }} / H=q_{h a b} R_{h} / H$

Em que:

$A_{\text {hab }}, V_{\text {hab }}=$ área e volume per capita da lagoa de polimento

$\mathrm{H}=$ profundidade da lagoa

$\mathrm{R}_{\mathrm{h}}=$ tempo de permanência

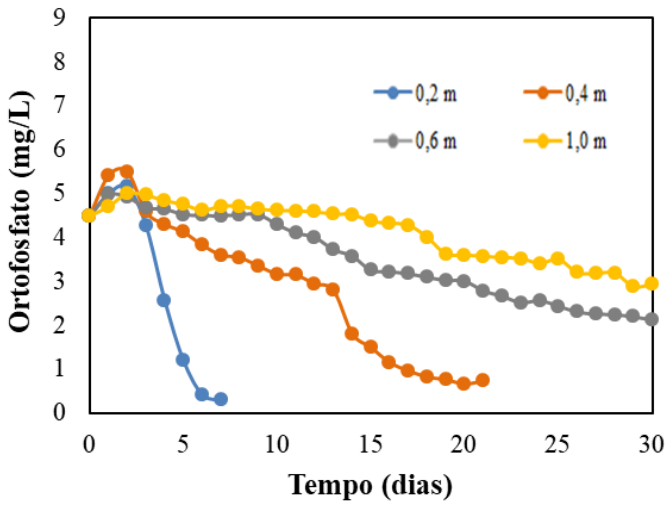

Usando os resultados das investigações mencionadas acima, foram plotados na Fig. 6 em função da profundidade das LPBS os valores da área por habitante necessária para realizar os diferentes objetivos do tratamento: remoção de material orgânico, dos coliformes, de nitrogênio e de fósforo. A Fig. 6 foi feita para uma contribuição per capita de 100 L.hab.d $^{-1}$, mas pode ser adaptada para qualquer outro valor, uma vez que a área é proporcional à contribuição. Os resultados obtidos e expressos graficamente na Fig. 6 indicam que:
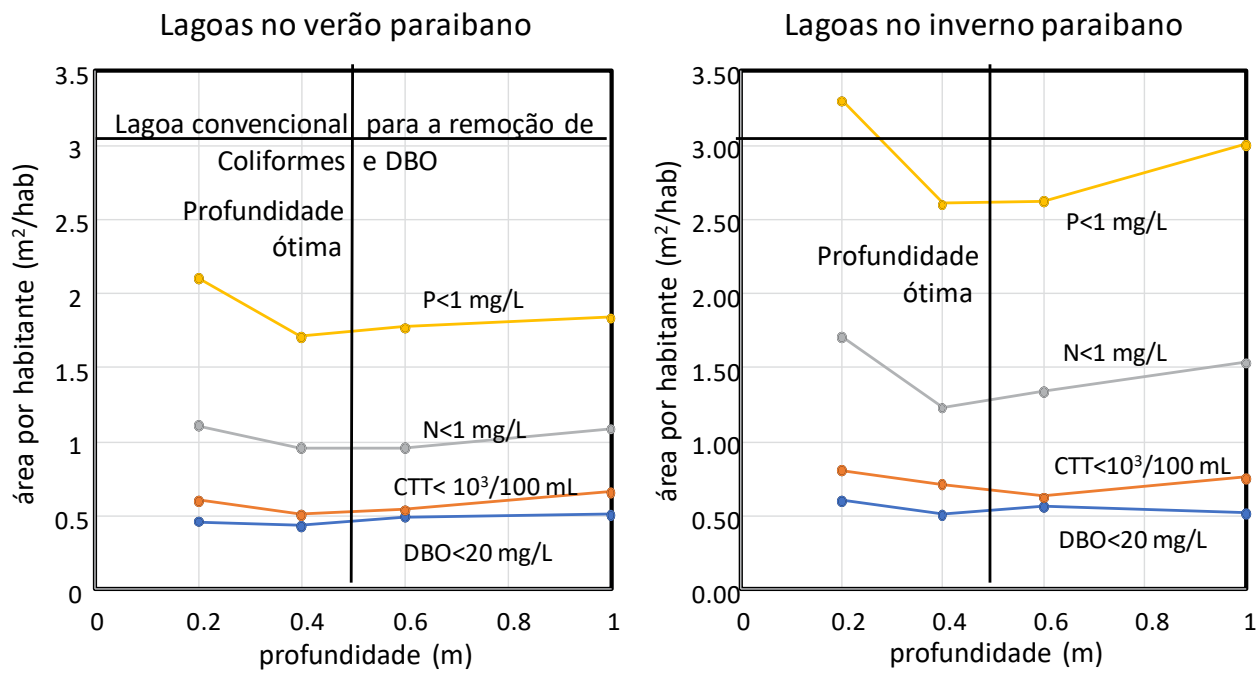

Figura 6 - Área per capita das LPBS em função da profundidade para remoção da DBO, dos coliformes termotolerantes, de nitrogênio amoniacal e de fosfato, para as condições de verão e de inverno (per capita contribuição de 100 L.hab.d ${ }^{-1}$ ). 
A. A área necessária para as LPBS removerem DBO e CTT é muito menor do que os valores necessários para as lagoas de estabilização convencionais, que é de cerca de $3 \mathrm{~m}^{2}$ por habitante. Os dados indicam que para LPBS sem remoção de nutrientes a redução da área comparada com LEs convencionais é um fator de 4 a 5 . Se a remoção de nitrogênio é necessária, a redução da área das LPBS é um fator 2 aproximadamente. Se a remoção de fósforo é desejada, a área das LPBS é mais ou menos equivalente à de uma LE;

B. A área das LPBS para a remoção de material orgânico e CTT somente é afetada marginalmente pelo clima e a profundidade. Em contraste, a área para remoção dos nutrientes depende desses fatores;

C. A profundidade das LPBS tem um valor ótimo para a remoção de nutrientes de cerca $0,5 \mathrm{~m}$;

D. A remoção de amônia requer uma área bem maior do que o valor para remoção de DBO;

E. A remoção de fósforo requer cerca do dobro da área necessária para a remoção de amônia.

Um aspecto importante é que a remoção de nutrientes geralmente é o objetivo do pós-tratamento somente quando o efluente final não é usado na agricultura. No reúso industrial ou na descarga do efluente final em águas de superfície, a remoção de nutrientes é necessária. Quando a água residuária é tratada para reúso industrial, é necessário ainda remover as algas que cresceram durante o pós-tratamento na LPBS. Uma possibilidade para tal fim é a clarificação (coagulação-floculação-sedimentação-filtração) do efluente da LPBS. Nesse caso, o uso de coagulante (normalmente policloreto/PAC ou sulfato de alumínio) irá remover o fosfato, de modo que nesse caso sua remoção na LPBS não é necessária. A suspensão de algas após a coagulação pode ser digerida num digestor específico ou no próprio reator UASB.

\section{APLICAÇÕES DO NOVO SISTEMA DE TRATAMENTO DE ESGOTO}

A aplicação mais óbvia e imediata do sistema UASB-LPBS proposto é a transformação dos inúmeros sistemas de lagoas de estabilização convencionais em sistemas com pré-tratamento eficiente (reatores UASB) seguido por lagoas de polimento de bateladas sequenciais. Não somente a população no entorno dos sistemas de LEs será beneficiada, ao se livrar dos odores incômodos, mas também há significativos ganhos ambientais, como: a queima do biogás, em vez da liberação para a atmosfera, e a proteção dos corpos receptores, evitando a eutrofização. Em regiões com recursos hídricos escassos, uma das mais importantes melhorias trazidas com o novo sistema de tratamento é a possibilidade de gerar uma nova fonte de água para utilização nas indústrias, reduzindo-se, assim, a demanda de água e destravando as amarras de desenvolvimento econômico que a falta de água provoca.

Sistemas compostos por reatores UASB-LPBS podem ser muito mais baratos do que sistemas convencionais de LEs por dois motivos: (1) podem ser construídos perto das regiões urbanas (ou mesmo dentro delas), reduzindo-se assim os custos do emissário final e, (2) redução dos custos por causa da redução da área para implantação do sistema, bem como da altura dos taludes das lagoas, que será muito menor. Além disso, como as várias LPBS operam de modo independente umas das outras, estas podem ser construídas em níveis diferentes em terrenos com topografia acidentada, reduzindo os custos de terraplanagem.

O sistema UASB-LPBS é aplicável em qualquer escala, ainda que geralmente não seja usado em grandes aglomerações urbanas por requerer uma área considerável, embora muito menor que a do sistema de LEs convencional. O sistema pode também ser aplicado para vazões pequenas: na zona rural, na ausência de rede coletora 
de esgoto, abre-se a possibilidade de construção de sistemas unifamiliares com reúso do efluente para a produção de alimentos nas propriedades.

\section{REENGENHARIA DOS SISTEMAS DE LAGOAS DE ESTABILIZAÇÃO}

Foram apresentados argumentos para mostrar que a inclusão de um reator UASB como unidade de pré-tratamento é uma boa alternativa. $O$ uso desse reator em substituição à LAn-LF permite uma modificação radical no tamanho e na configuração das lagoas como unidade de pós-tratamento, bem como uma melhoria na qualidade do efluente final. $\mathrm{Na}$ Tabela 3 apresentam-se a composição e as dimensões das quatro alternativas: (I) LE, (II) UASB-LPBS para remoção de material orgânico e coliformes termotolerantes, (III) remoção adicional de nitrogênio, na configuração UASB-LPBS e (IV) remoção adicional de nitrogênio e fósforo, também na configuração UASB-LPBS.

Tabela 3 - Comparação da configuração de: (I) Lagoas de estabilização convencional (LE), (II) UASB-LPBS para remoção de material orgânico e coliformes termotolerantes, (III) UASB-LPBS para remoção de nitrogênio, e (IV) UASB-LPBS para remoção de fósforo (LPBS com 0,5 m de profundidade).

\begin{tabular}{|c|c|c|c|c|}
\hline \multirow{2}{*}{ Sistema } & I & II & III & IV \\
\hline & LE & UASB+LPBS & UASB+LPBS & UASB+LPBS \\
\hline Objetivos (Remoção de:) & *MO e CTT & MO e CTT & MO, CTT e nitrogênio & $\begin{array}{l}\text { MO, CTT, nitrogênio e } \\
\text { fósforo }\end{array}$ \\
\hline \multicolumn{5}{|l|}{ COMPOSIÇÃO } \\
\hline Trat. preliminar & + & + & + & + \\
\hline LAn & + & & & \\
\hline LF & + & & & \\
\hline LM & + & & & \\
\hline UASB & & + & + & + \\
\hline LP & & + & + & + \\
\hline Clarificação & & & & + \\
\hline Digestão de algas & & & & + \\
\hline \multicolumn{5}{|l|}{ DIMENSÕES } \\
\hline TDH (Total) (dias) & $2 / 14 / 14=26$ & $0,25+6=6,25$ & $0,25+12=12,2$ & $0,2+25=25,2$ \\
\hline Profundidade (m) & $4 / 1,2 / 1,0$ & $5 / 0,5$ & $5 / 0,5$ & $5 / 0,5$ \\
\hline Área per capita $\left(\mathrm{m}^{2}\right)$ & $0,05+1,2+1,4=2,65$ & $0,01+0,6=0,61$ & $0,01+1,3=1,31$ & $0,01+2,6=2,61$ \\
\hline Volume per capita $\left(\mathrm{m}^{3}\right)$ & 2,65 & 0,62 & 1,2 & - \\
\hline
\end{tabular}

Legenda: "MO - Material orgânico; CTT - Coliformes termotolerantes; TDH - Tempo de detenção hidráulica (dias); Trat. - tratamento.

Mostrou-se que para todas as profundidades pesquisadas (faixa de 0,2 a $1,0 \mathrm{~m}$ ) sempre o ambiente nas LPBS era aeróbio e a concentração de OD aumentava de um valor $\approx 0$, no início de uma batela$\mathrm{da}$, atingindo rapidamente um valor médio acima da concentração de saturação nas lagoas rasas.

Se o $\mathrm{pH}$ elevado do efluente final for tido como um problema, pode-se dissolver parte do $\mathrm{CO}_{2}$ depois da queima do biogás gerado no UASB, o que leva a uma redução do $\mathrm{pH}$. Essa carbonatação pode ser realizada em uma unidade à parte com um tempo de permanência curto (minutos). Por outro lado, se houver interesse em estimular o crescimento de algas, pode-se dissolver o $\mathrm{CO}_{2}$ na LPBS e assim acelerar a taxa de fotossíntese e a produção de algas. As algas podem então ser usadas para geração de energia (digestão anaeróbia e combustão do resíduo não biodegradável) ou biomassa para diferentes finalidades.

Um aspecto importante na qualidade do efluente final é o aumento da salinidade durante o tratamento na LPBS. Esse aumento na salinida- 
de depende diretamente da perda de água por evaporação, que pode ser bastante significativa em regiões áridas e quentes, e no caso do uso de LE pode haver períodos sem a produção de um efluente final com a totalidade de esgoto evaporado. A evaporação da água depende basicamente de dois fatores: a taxa de evaporação da água e a área da lagoa exposta à atmosfera.
A Tabela 4 resume os valores que caracterizam a qualidade do efluente das diferentes alternativas (I) a (IV). A DBO da combinação UASB-LPBS é sempre bem menor que a DBO final da LE. A eficiência da remoção do material orgânico nas LPBS que removem nitrogênio e fósforo tende a ser menor que na LPBS sem remoção de nutrientes (mais crescimento de algas).

Tabela 4 - Comparação da qualidade do efluente de 4 configurações: (I) Lagoas de estabilização convencional (LE), (II) UASB-LPBS para remoção de material orgânico e coliformes termotolerantes, (III) UASB-LPBS para remoção de nitrogênio e (IV) UASB-LPBS para remoção de fósforo (LPBS com 0,5 m de profundidade).

\begin{tabular}{|c|c|c|c|c|c|}
\hline \multirow{2}{*}{ Parâmetro / Qualidade } & 0 & 1 & II & III & IV \\
\hline & Esgoto Bruto & LE & UASB-LPBS & UASB-LPBS & UASB-LPBS \\
\hline $\mathrm{DBO}\left(\mathrm{mg} \cdot \mathrm{L}^{-1}\right)$ & 500 & 100 & 30 & 40 & 50 \\
\hline DQO (mg.t-1) & 800 & 200 & 100 & 150 & 200 \\
\hline CTT (NMP) & $10^{8}$ & $<10^{3}$ & $<10^{3}$ & $<10^{3}$ & $<10^{3}$ \\
\hline $\mathrm{pH}(-)$ & 7 & 7 & 7 & 9 & 9,7 \\
\hline NTK $\left(m g \cdot L^{-1}\right)$ & 60 & 100 & 70 & $<1$ & $<1$ \\
\hline$P\left(m g . L^{-1}\right)$ & 10 & 20 & 12 & 20 & $<1$ \\
\hline $\mathrm{S}\left(\mathrm{mg} \cdot \mathrm{L}^{-1}\right)$ & 5 & $<1$ & $<1$ & $<1$ & $<1$ \\
\hline Salinidade $\left(\mathrm{mg} \cdot \mathrm{L}^{-1}\right)$ & 600 & 800 & 900 & 900 & 1000 \\
\hline
\end{tabular}

\section{CONFIGURAÇÃO DO SISTEMA UASB-LPBS}

Quanto à configuração, tem-se principalmente que o sistema convencional de lagoas em série e com fluxo contínuo (LAn-LF-LM) é substituído por um UASB e uma série de LP operando em paralelo e sob um regime de bateladas sequenciais. A LPBS é preferível à LPFC porque nelas é possível atingir os objetivos do tratamento em menos tempo, reduzindo-se, portanto, o volume e a área. Esse regime de bateladas é possível graças à baixa concentração de material biodegradável no efluente do reator UASB.

Tendo-se definido a área e a profundidade do sistema UASB-LPBS, é necessário determinar o número de lagoas a serem implantadas. Se o objetivo da LPBS é somente a remoção de CTT e DBO há basicamente duas configurações (FRUTUOSO; SANTOS; VAN HAANDEL, 2021):

(1) Série de lagoas projetada para receber o efluente do UASB sequencialmente, em cada lagoa (Figura 7a).
Nessa configuração o tempo de permanência para o decaimento dos CTT é contado a partir do momento em que o efluente do UASB enche a lagoa e passa a alimentar a próxima lagoa da série. Por conveniência operacional, pode-se escolher o volume da lagoa tal que o tempo de encher uma lagoa seja um dia. Assim, o tempo de permanência total na lagoa será o tempo de enchimento (1 dia) mais o tempo de decaimento.

(2) Série de lagoas recebendo o efluente de uma lagoa de transbordo intermediária entre o UASB e as LPBS (Fig. 7b).

Nessa configuração, a lagoa de transbordo tem a função de tanque de equalização, na qual é recebido um fluxo contínuo de efluente do UASB, enquanto as bateladas são descarregadas na lagoa, permitindo o regime de bateladas sequenciais nelas. A lagoa de transbordo não é somente um tanque de equalização, mas funciona também como um decantador de sólidos sedimentáveis que eventualmente venham a sair no efluente do 
UASB - e que pode ser uma fração de 30 a $50 \%$ dos sólidos produzidos (VAN HAANDEL; VAN DER LUBBE, 2019). É possível ainda que a fotossíntese se inicie na lagoa de transbordo, bem como pode ocorrer remoção de sulfeto (FRUTUOSO; SANTOS; VAN HAANDEL, 2021).

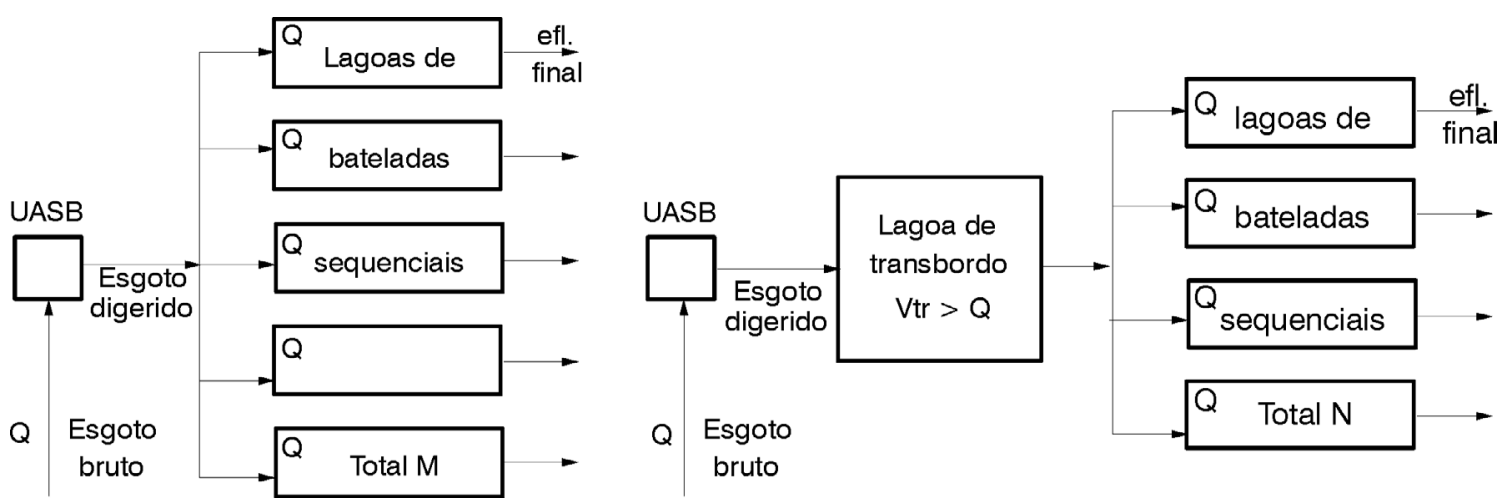

Figura 7 - Esquema da disposição e operação de lagoas de polimento alimentadas em bateladas sequenciais sem (7a, esquerda) e com (7b, direita) uma lagoa intermediária de transbordo.

\section{CONCLUSÕES}

O sistema convencional de lagoa de estabilização (LE) de águas residuárias apresenta desvantagens e sua aplicação no tratamento de esgoto deve ser evitada. As desvantagens se referem aos seguintes problemas: (1) tamanho do sistema de tratamento; (2) à qualidade do efluente; (3) problemas ambientais; (4) custos de construção; (5) problemas operacionais.

(1) Com relação ao tamanho do sistema de tratamento, a área muito grande não apenas limita a aplicabilidade da LE, mas o tempo de retenção muito longo também causa evaporação extensa, reduzindo a quantidade e a qualidade (salinidade) do efluente e afetando sua aplicabilidade para reutilização agrícola.

(2) No que diz respeito à qualidade do efluente, um problema sério é que a remoção de nutrientes não é possível, de modo que a qualidade do efluente não é compatível com as normas legais e, por conseguinte, não pode ser lançado nas águas superficiais. Além disso, a reutilização industrial de efluente rico em nutrientes é muito problemática.
(3) Com relação aos problemas ambientais, a liberação do biogás produzido tende a criar problemas de odor, o que contribui muito para a impopularidade do sistema entre a população contribuinte. Além disso, a liberação de metano no biogás torna o sistema o maior contribuinte de gases do efeito estufa entre todos os sistemas de tratamento.

(4) Os custos de construção referem-se ao sistema de coleta de esgoto e ao próprio sistema de tratamento. Os custos do sistema de coleta são altos porque apenas um sistema pode ser usado em uma região urbana específica e deve ser construído longe das áreas povoadas para evitar problemas de odor, exigindo um emissário longo com um alto custo.

(5) Um importante problema operacional é a necessidade de realizar a dragagem da lagoa anaeróbia em um curto intervalo, poucos anos (3-5 anos), uma operação complicada e demorada.

Todos os problemas inerentes à LE podem ser eliminados ou reduzidos pela aplicação de um reator UASB para tratar o esgoto bruto e as lagoas 
de polimento (LP) para o pós-tratamento em vez de lagoas facultativas ou de maturação.

(1) O pré-tratamento eficiente reduz a demanda de produção de oxigênio fotossintético e abre caminho para uma redução considerável do tempo de retenção e consequentemente do tamanho do sistema UASB-LP.

(2) A predominância da fotossíntese sobre a oxidação do material orgânico leva ao consumo de dióxido de carbono e ao aumento do $\mathrm{pH} . \mathrm{O} \mathrm{pH}$ alto permite a remoção de nutrientes: nitrogênio, devido à dessorção de amônia, e fósforo, devido à precipitação de fosfato. Assim, pode ser produzida uma qualidade final de efluente compatível com as normas legais.

(3) O reator UASB captura a produção de biogás, que pode ser usada produtivamente ou queimada. Assim, os problemas de odores e as emissões de GEE são bastante reduzidos.

(4) Devido à ausência virtual de problemas de odor, o sistema UASB-LP pode ser construído próximo ou mesmo dentro das regiões urbanas, evitando altos custos do sistema de coleta. Além disso, a forte redução da área de LP leva a uma importante redução de custos e pode aumentar sua aplicabilidade. Outro fator de redução de custos é que a profundidade da LP é muito menor que a da LE, o que reduz os custos de escavação e de construção de taludes.

(5) Os sólidos não biodegradáveis podem ser descarregados periodicamente do reator UASB e secos em leitos de secagem para uso como fertilizante orgânico.

As unidades de lagoa de polimento podem ser operadas como lagoas de fluxo contínuo (LPFC) ou batelada sequencial (LPBS). A LPBS deve ser preferida, pois permite uma redução considerável do tempo de retenção em comparação com o LPFC em condições comparáveis.
As lagoas de polimento podem melhorar a qualidade do efluente do UASB em quatro aspectos: (1) redução do material orgânico residual; (2) remoção dos coliformes termotolerantes (CTT); (3) remoção de amônia (N) e (4) remoção de fósforo (P).

A profundidade ótima para a LPBS é de cerca de $0,5 \mathrm{~m}$ e a área per capita requerida depende da qualidade desejada para o efluente.

\section{AGRADECIMENTOS}

Os autores agradecem ao Conselho Nacional de Desenvolvimento Científico e Tecnológico (CNPq) pelo incentivo financeiro as pesquisas.

\section{CONTRIBUIÇÃO DOS AUTORES}

Todos os autores contribuíram de forma igualitária.

\section{REFERÊNCIAS}

AGUIAR, M. R. L.; SANTOS, S. L.; VAN HAANDEL, A. Lagoas de polimento operando em bateladas como pós-tratamento de reatores UASB: remoção de material orgânico. Revista DAE: Edição especial, São Paulo, n. 229, março 2021.

ALBUQ_UERQQUE, M. S.; SANTOS, S. L.; VAN HAANDEL, A. Influência do regime hidrodinâmico sobre o desempenho de lagoas de polimento. Revista DAE: Edição especial, São Paulo, n. 229, março 2021.

BASTOS, R. K. X. RIOS E.N. E SÁNCHEZ I. A. Further contributions to the understanding of nitrogen removal in waste stabilization ponds. Water Sci Technol vol. 77 n. 11, p. 2635-2641, 2018.

BATISTA, M. M.; LAMBAIS, G. R.; SANTOS, S. L.; VAN HAANDEL, A. Decaimento bacteriano em lagoas de polimento tratando efluente de reator UASB. Revista DAE: Edição especial, São Paulo, n. 229, março 2021.

BRASIL. Ministério do Meio Ambiente. CONAMA. Resolução nº 357, de 17 de março de 2005: Dispõe sobre a classificação dos corpos de água e diretrizes ambientais para o seu enquadramento, bem como estabelece as condições e padrões de lançamento de efluentes, e dá outras providências. Diário Oficial da União, Brasília, 2005.

BRASIL. Ministério do Meio Ambiente. CONAMA. Resolução $n^{\circ}$ 430, de 13 de maio de 2011: Dispõe sobre as condições e padrões 
de lançamento de efluentes, complementa e altera a Resolução no 357, de 17 de março de 2005, do Conselho Nacional do Meio Ambiente-CONAMA. Diário Oficial da União, Brasília, 2011.

CAMARGO VALERO, M. A; MARA, D. D. Ammonia volatilisation in waste stabilisation ponds: a cascade of misinterpretations? Water Sci Technol., v. 61, n. 3, p. 555-61, 2010. https://doi.org/10.2166/ wst. 2010.856

CAMPOS, J. R. Tratamento de esgoto sanitário por processo anaeróbio e disposição controlada no solo. PROSAB (Programa Nacional de Saneamento Básico). Rio de Janeiro - RJ, p. 435, 1999.

CAVALCANTI P. F. F. Integrated Application of the UASB Reactor and Ponds for Domestic Sewage Treatment in Tropical Regions. (PhD thesis) - University of Wageningen, The Netherlands, 2003.

CAVALCANTI, P. F. F.; VAN HAANDEL, A.; LETTINGA, G. Polishing ponds for post-treatment of digested sewage part 1: flow-through ponds. Water Science and Tecnhology. V.44, n.4, p. 237-245, 2001.

FRUTUOSO, F. K. A.; SANTOS, S. L.; VAN HAANDEL, A. Lagoas de transbordo aplicadas para o melhoramento de efluentes anaeróbios destinados a lagoas de polimento. Revista DAE: Edição especial, São Paulo, n. 229, março 2021.

HO, L. T.; ECHELPOEL, W. V.; GOETHALS, P. L. M. Design of waste stabilization pond systems: A review. Water Research, vol. 123, p. 236-248, 2017. https://doi.org/10.1016/j.watres.2017.06.071

INSTITUTO BRASILEIRO DE GEOGRAFIA E ESTATÍSTICA - IBGE. Pesquisa nacional de saneamento básico - 2008, 2010. Disponível em: < http://www.ibge.gov.br>. Acesso em: 20 fev. 2020.

JORDÃO, E. P.; PESSÔA, C. A. Tratamento de Esgotos Domésticos. 8. ed. Rio de Janeiro: Abes, 2017. 928 p.

LEVENSPIEL, O. Chemical Reaction Engineering, 4th edn. Wiley, New York, USA, 2003.

MARA, D. D.; PEARSON, H. W. Design manual for waste stabilization ponds in Mediterranean countries. Leeds: Lagoon Technology International, 1998.

MARA, D. D. Design Manual for Waste Stabilization Ponds in India. Leeds: Lagoon Technology International. 1997. 125p.
MARA, D. D. Proposed design for oxidation ponds in hot climates. J. Environ. Eng. Division-Asce, v. 101, p. 296-300, 1976.

MARAIS, G. V. R. Faecal bacterial kinetics in stabilisation ponds. J. Environ. Eng. Division-Asce, v. 100, p. 119-139, 1974.

MARAIS, G.V.R. e SHAW V.A. A rational theory for the design of sewage stabilizarion ponds in Central and South Africa. Trans. S. Afr. Instn. Civ. Engrs, 3, 1964.

OAKLEY, S. M. Lagunas de estabilizácion en Honduras: manual de diseño, construcción, operación y mantenimiento, monitoreyo y sostentibilidad. Universidade Estatal de California. 2005. 247p.

PANO, A. E; MIDDLEBROOKS, J. Ammonia Nitrogen Removal in Facultative Wastewater Stabilization Ponds. Journal Water Pollution Control Federation, v. 54, n. 4, 1982. https://doi. org/10.2307/25041312

PARKER, C. D.; JONES, H. L.; TAYLOR, W. S. Purification of Sewage in Lagoons. Sewage and Industrial Waste, v. 22, n. 6, p. 760-775, 1950. https://doi.org/10.2307/25031317

SANTOS, I. V.; SANTOS, S. L.; VAN HAANDEL, A. Remoção de fósforo em lagoas de polimento operadas em regime de bateladas sequenciais. Revista DAE: Edição especial, São Paulo, n. 229, março 2021.

SANTOS, S. L.; VAN HAANDEL, A. Variação do pH e remoção de nitrogênio em lagoas de polimento. Revista DAE: Edição especial, São Paulo, n. 229, março 2021.

VAN HAANDEL, A. C.; LETTINGA, G. Anaerobic sewage treatment: a practical guide for regions with a hot climate. John Wiley and Sons, 1994, 222p.

VAN HAANDEL, A.C.; VAN DER LUBBE, J. Anaerobic sewage digestion: Theory and applications. International Water Association Londres RU, 2019.

ZIMMO, O. R; VAN DER STEEN, N. P; GIJZEN, H. J. Comparison of ammonia volatilization rates in algae and duckweed-based waste stabilization ponds treating domestic wastewater. Water Research, v. 37, p. 4587-4594, 2003. https://doi.org/10.1016/j.watres.2003.08.013 